\title{
MELHORIA NA QUALIDADE DA ÁGUA PELA \\ IMPLANTAÇÃO DE UM NOVO SISTEMA DE \\ TRATAMENTO DE EFLUENTE INDUSTRIAL NA \\ REFINARIA REPLAN/PETROBRAS
}

\section{IMPROVEMENTS ON WATER QUALITY BY A NEW WASTEWATER TREATMENT SYSTEM IN REPLAN/PETROBRAS OIL REFINARY}

\section{Wieczorek, A. ${ }^{1}$, Angelis, D. F. ${ }^{2}$, Furlan, L. T. ${ }^{3}$; Corrêa Jr., B. ${ }^{3}$}

${ }^{1}$ Departamento de Geologia Aplicada da UNESP/Rio Claro - artwiec@rc.unesp.br

${ }^{2}$ Departamento de Bioquímica e Microbiologia da UNESP/Rio Claro dangelis@rc.unesp.br

${ }^{3}$ PETROBRAS, Refinaria de Paulínia - REPLAN. furlan@petrobras.com.br, bentaci@petrobras.com.br

\section{RESUMO}

As refinarias de petróleo utilizam diariamente grande quantidade de água nos processos de refino de óleo. Durante estes processos são geradas complexas misturas de substâncias químicas potencialmente poluidoras dos corpos hídricos. Para minimizar o efeito poluidor do efluente, em setembro de 2002, a Refinaria de Paulínia- REPLAN/PETROBRAS, implantou um novo sistema de tratamento baseado em processos biológicos de lodos ativados. Neste trabalho avaliou-se a qualidade do efluente gerado pela REPLAN/PETROBRAS e da água do Rio Atibaia, receptor do efluente, nas fases pré e pós implantação do novo sistema. Foram coletadas amostras de água quinzenalmente, acima e abaixo do ponto de entrada do efluente no rio, no período de julho de 2001 a março de 2003. Foram quantificados Oxigênio Dissolvido (OD), Demanda Bioquímica de Oxigênio (DBO) e Amônia $\left(\mathrm{NH}_{3}\right)$, assim como os parâmetros para o cálculo do Índice de Qualidade da Água (IQA), adotado pela Companhia de Tecnologia e Saneamento Ambiental - CETESB (1987), para classificação desse ecossistema. Foi realizado um teste t para verificar a influência do novo sistema de tratamento sobre os parâmetros analisados do efluente, comparando-se os períodos pré e pós-implantação. Os resultados demonstraram que o novo sistema de tratamento alterou os parâmetros analisados no sentido de melhoria da qualidade da água do efluente. Os valores médios de OD passaram de 5,0 para 8,0 mg. $\mathrm{L}^{-1}$, DBO de 30,0 para 5,0 mg. $\mathrm{L}^{-1}$ de $\mathrm{O}_{2}, \mathrm{NH}_{3}$ de 29,7 para $0,47 \mathrm{mg} . \mathrm{L}^{-1}$, o IQA de 29 para 44, classificação ruim para regular, da fase pré para a fase pós-implantação 
do novo sistema. Este estudo demonstrou que este sistema, baseado no tratamento biológico por lodos ativados, é mais eficiente que aquele anteriormente usado pela refinaria.

Palavras-Chave: Refinaria de petróleo; efluente industrial; qualidade da água; tratamento de efluentes; índice de qualidade da água.

\begin{abstract}
Oil refineries use day-to-day large amounts of water in their processes. During those processes complexes chemical mixtures are generated with potential to pollute water bodies. To minimize the pollution effect of wastewater, the refinery of Paulínia- REPLAN/PETROBRAS (Refinaria de Paulinia/Petrobras) introduced a new system of treatment in September 2002, based on biological process of activated sludge. This investigation evaluated the quality of wastewater and water of Atibaia River, the receiving of wastewater, in periods before and after the introduction of the new system. Water samples were collected every two weeks between July 2001 and March 2003, both upstream and downstream from the refinery. The parameters analyzed were Dissolved Oxygen (DO), Biochemical Oxygen Demand (BOD), Ammonia Water $\left(\mathrm{NH}_{3}\right)$, and the parameters used on computation of Water Quality Index (WQI), accepted by CETESB (1987), to classify this ecosystem. The t-test was used to verify the influence of the new wastewater treatment system on the parameters of wastewater, confronting the periods before and after the new system. The results demonstrated that the new wastewater treatment system significantly improved wastewater quality. Averages values of DO changed from 5,0 to $8,0 \mathrm{mg} . \mathrm{L}^{-}$ 1, BOD from 30,0 to $5,0 \mathrm{mg} . \mathrm{L}^{-1}, \mathrm{NH}_{3}$ from 29,7 to $0,47 \mathrm{mg} . \mathrm{L}^{-1}$, WQI from 29 to 44 , classification from "bad" to "regular", from the period before to after introduction of the new system. This study has proven that the new system, based on biological treatment by activated sludge, is more efficient than the previous system used by the oil refinery.
\end{abstract}

Key words: Oil refinery, wastewater, water quality, wastewater treatment, water quality index.

\title{
1. INTRODUÇÃO
}

O número de produtos químicos disponíveis e utilizados pelo homem está na ordem de centenas de milhares, grande parte deles possuindo potencial para persistir no meio ambiente. Dentre os ecossistemas, os aquáticos acabam de uma forma ou de 
outra constituindo os receptáculos temporários ou finais de grande variedade e quantidade de poluentes, sejam estes dispersos no ar, no solo, ou diretamente nos corpos de água (GOLDSTEIN, 1988).

O crescente comprometimento da qualidade dos ecossistemas aquáticos tem sido causado não só pelo excesso de esgotos domésticos lançados sem tratamento nos corpos hídricos, como pela variedade de resíduos químicos e orgânicos provenientes de descartes industriais e agrícolas que perfazem extensa gama de substâncias potencialmente tóxicas (LANDIS e YU, 1985).

Nesse contexto, as refinarias de petróleo, nos processos de lavagem do óleo cru, refino do petróleo bruto, resfriamento das torres de destilação e produção de vapor em caldeiras utilizam grande volume de água. Contudo, nessas unidades, empregam-se os tratamentos químicos e biológicos destas águas, gerando-se o efluente final. Cada etapa do processo pode acrescentar ao efluente complexas misturas de substâncias químicas. Estima-se que para cada metro cúbico de óleo refinado, dois metros cúbicos de água são utilizados nas diversas fases do processo. $\mathrm{Na}$ Refinaria de Paulínia, após a implementação de inúmeras ações de reuso de água em suas unidades de processo, passou-se a utilizar 0,67 metros cúbicos de água para cada metro cúbico de petróleo processado.

Brito (1996), destaca que as substâncias encontradas com mais freqüência nos efluentes das refinarias de petróleo são as soluções cáusticas residuais, sulfídricas, fenólicas, amoniacais e de hidrocarbonetos. A autora destacou que a amônia presente no efluente das refinarias petrolíferas tem origem principalmente durante a quebra dos compostos orgânicos nitrogenados nos processos de conversão, e na adição da substância diretamente na linha de processo para controlar a corrosão.

Wieczorek et al, (2003), após avaliação do efluente da refinaria no período de julho a dezembro de 2001, observaram que o mesmo apresentava problemas no tocante aos compostos orgânicos, principalmente quanto a $\mathrm{DBO}$ e a $\mathrm{NH}_{3}$, sendo necessário à melhoria da qualidade do tratamento para diminuição destes parâmetros.

Em maio de 2002 a refinaria iniciou a implantação de um novo processo biológico na sua estação de tratamento de efluentes, constituído por sistemas biológicos de lodos ativados, com o objetivo de realizar o tratamento para diminuição de nitrogênio total, especialmente a $\mathrm{NH}_{3}$, sendo que a implantação foi considerada encerrada quando os valores de $\mathrm{NH}_{3}$ atingiram valores próximos de zero (setembro de 2003).

Os sistemas de lodos ativados estão sendo amplamente utilizados em nível mundial, para o tratamento de despejos domésticos e industriais. Estes processos aplicam-se em situações que sejam necessárias elevadas qualidades dos efluentes a serem descartados nos corpos receptores (CONEGLIAN, 2001).

Segundo Von Sperling (1997), o sistema de lodos ativados é um processo de tratamento biológico onde a alta concentração de microrganismos é mantida em suspensão no reator, e o oxigênio é introduzido por meio de aeradores mecânicos ou 
difusores de ar. No tratamento biológico aeróbio, o oxigênio deve ser fornecido para satisfazer às seguintes demandas: oxidação da matéria orgânica e nitrificação.

Sendo assim, o objetivo deste estudo foi verificar a eficiência deste novo processo implantado no sistema de tratamento mediante o monitoramento da qualidade do efluente e da água do Rio Atibaia à montante e à jusante da refinaria.

\section{METODOLOGIA}

A refinaria de petróleo REPLAN/PETROBRAS localiza-se na cidade de Paulínia e faz parte do Pólo Petroquímico de Paulínia. Capta água do Rio Jaguarí e descarta seu efluente no Rio Atibaia (Fig 1). Estes dois rios, em confluência, formam o Rio Piracicaba. O Rio Atibaia recebe nesta região grande aporte de esgoto urbano vindo das cidades de Campinas, Sumaré e Paulínia, fazendo com que a qualidade da água deste corpo hídrico seja deteriorada neste ponto (CETESB, 2002).

A Refinaria de Paulínia possui na sua Estação de Tratamento de Efluentes Líquidos um tratamento primário baseado em processo físico-químico para separação e remoção do óleo da água, seguido de tratamento secundário biológico em reatores anóxicos e reatores aeróbios (processo de desnitrificação e nitrificação baseado na tecnologia de lodos ativados).

Em conjunto com os sistemas de tratamento de efluentes, desenvolveu-se um programa de monitoramento da qualidade do efluente e da água do Rio Atibaia à montante e à jusante do ponto descarte do efluente no rio. O objetivo deste monitoramento foi acompanhar a qualidade da água do efluente e sua influência sobre as águas do Rio Atibaia.

Para o desenvolvimento deste estudo foram analisadas amostras superficiais de água do Rio Atibaia e do efluente da refinaria, coletadas quinzenalmente no período de julho de 2001 a março de 2003, com exceção do período de janeiro a junho de 2002.

As amostras de água do Rio Atibaia foram colhidas 200 metros à montante (ponto 1) e 600 metros à jusante (ponto 3 ) do descarte do efluente da indústria no Rio Atibaia, e amostras do efluente colhidas no ponto de saída da indústria localizado no final do tratamento biológico (ponto 2). Foram realizadas análises químicas e físicas das amostras, e calculados os respectivos índices de qualidade da água (IQA), proposto pela CETESB (2002). Os resultados do IQA foram comparados com o índice divulgado pela CETESB $(2002,2003,2004)$, para um ponto de análise no Rio Atibaia distante aproximadamente dois quilômetros à jusante da indústria (ponto 4, Figura 1). Para avaliação da vazão do Rio Atibaia no período, e sua influência sobre os parâmetros analisados, foram utilizados dados de vazão média mensal divulgado por CETESB, $(2002,2003,2004)$ do mesmo ponto utilizado no índice de qualidade da água. Figura 7. 


\begin{tabular}{|l|r|}
\hline Recebido em: $28 / 09 / 2004$ & HOLOS Environment, v.5 n.1, 2005 - P. 27 \\
\hline Liberado para Publicação em: $24 / 05 / 2005$ & ISSN: $1519-8634$ \\
\hline
\end{tabular}

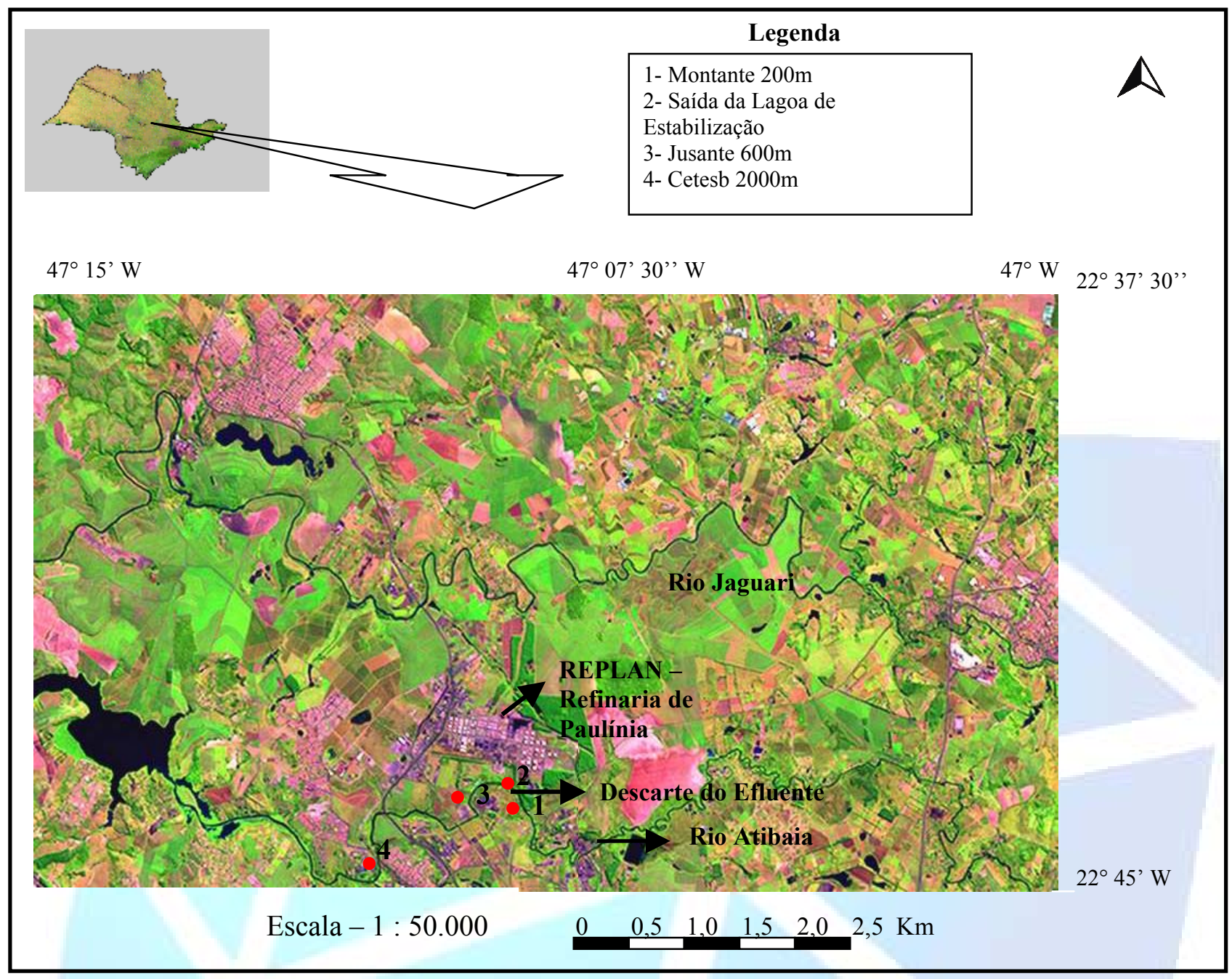

Figura 1 - Localização da REPLAN - Refinaria de Paulínia, e dos pontos de coleta das amostras de água. Fonte: modificado de EMBRAPA (2004).

\subsection{Análises Químicas e Físicas.}

Os seguintes parâmetros foram analisados e suas respectivas metodologias: oxigênio dissolvido (OD) utilizando-se leituras diretas das amostras com auxílio de

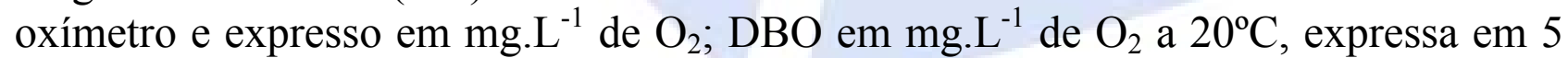

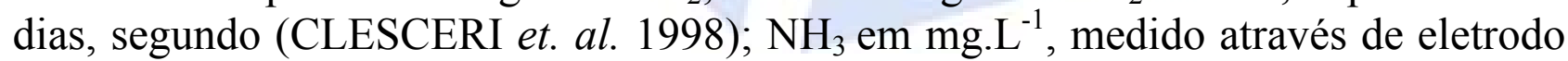
íon seletivo.

\section{2. Índices de Qualidade da Água (IQA)}

O índice de qualidade da água proposto pela CETESB (2002), considera um conjunto de nove parâmetros para seu cálculo. Estes parâmetros são: coliformes fecais, $\mathrm{pH}, \mathrm{DBO}$, nitrogênio total, fósforo total, temperatura, turbidez, resíduo total e oxigênio dissolvido. Coliformes fecais foram determinados utilizando Substrato Cromogênico segundo Clesceri et. al. (1998). O pH foi determinado utilizando-se potenciômetro. Nitrogênio, fósforo e resíduos totais foram determinados segundo 
Clesceri et. al. (1998). A temperatura foi determinada in situ, a turbidez foi quantificada segundo o método de $\mathrm{HACH}$, mediante leituras diretas em turbidímetro, e expressa em Unidade Nefelométrica de Turbidez (NTU).

O IQA foi calculado com base no valor de cada parâmetro dado por uma curva de variação média e por um peso atribuído a cada um.

$$
\mathrm{IQA}=\prod_{\mathrm{i}=1}^{\mathrm{n}=9} \mathrm{q}_{\mathrm{i}}{ }^{\mathrm{Wi}}
$$

Onde: $\mathrm{q}_{\mathrm{i}}$ é o valor atribuído para cada parâmetro com relação a sua curva de variação média e $\mathrm{w}_{\mathrm{i}}$ é o peso atribuído a cada valor.

A partir do valor calculado pelo índice pode-se atribuir uma gradação de qualidade. Onde:

$$
\begin{array}{ll}
0<\text { IQA } \leq 19 & \text { qualidade péssima } \\
19<\text { IQA } \leq 36 & \text { qualidade ruim } \\
36<\text { IQA } \leq 51 & \text { qualidade regular } \\
51<\text { IQA } \leq 79 & \text { qualidade boa } \\
79<\text { IQA } \leq 100 & \text { qualidade ótima }
\end{array}
$$

\subsection{Análise Estatística.}

Para verificar a eficiência do sistema de tratamento de efluentes gerados na refinaria, foi preciso comparar os valores dos parâmetros de qualidade do efluente antes e após a implantação do mesmo. Para isso, se aplicou o teste t para comparação das médias dos parâmetros pré e pós-instalação (ZAR, 1996). Desta maneira foi realizada uma comparação dos valores médios dos parâmetros IQA, OD, DBO e $\mathrm{NH}_{3}$, no período de julho a dezembro de 2001(pré-instalação), com a média dos valores dos parâmetros no período de setembro de 2002 a março de 2003 (pósinstalação).

\section{RESULTADOS E DISCUSSÃO}

O tratamento do efluente implementado na refinaria implica, principalmente, na biodegradação mediante a oxidação biológica ou fotoquímica da matéria orgânica. Portanto, para que o processo de tratamento seja eficaz, os níveis de OD precisam ser suficientes para que os microrganismos aeróbios degradem os compostos presentes no efluente. Além disso, a ausência de oxigênio no processo de oxidação faz com que os microrganismos anaeróbios e ou facultativos realizem degradação, muitas vezes transformando-os em substâncias indesejadas como metano, gás sulfídrico e amônia, dependendo do substrato a ser degradado (DUFFUS, 1983). 


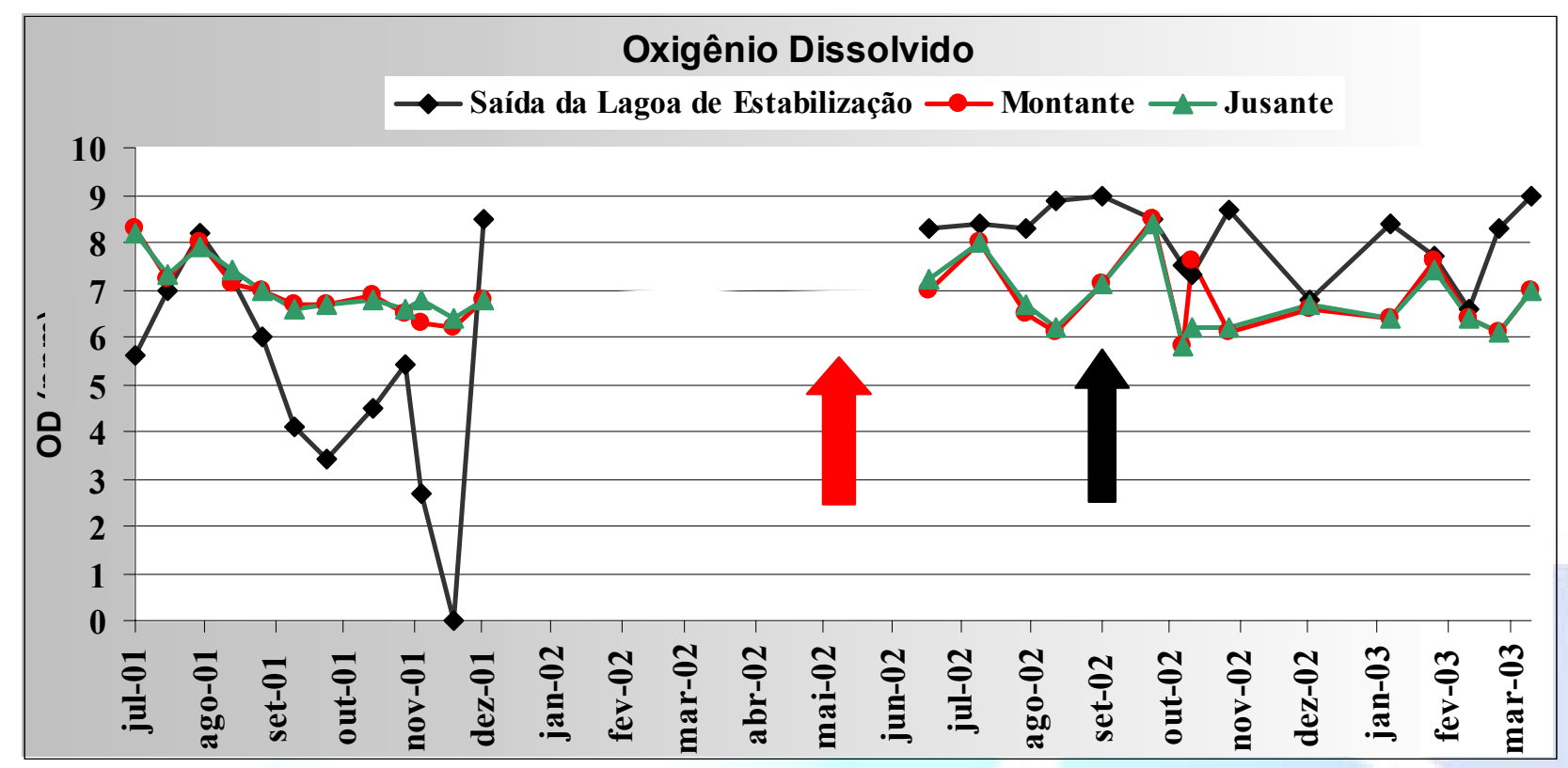

Figura 2 - Variação do oxigênio dissolvido (em mg. $\mathrm{L}^{-1}$ de $\mathrm{O}_{2}$ ) no período de julho de 2001 a março de 2003. A seta vermelha indica o início do novo sistema de tratamento e a seta preta indica o término da implantação do sistema de efluentes da indústria.

Verificando-se a Figura 2, no período de julho a novembro de 2001, o OD medido na saída da lagoa de estabilização, apresentou valores médios abaixo daqueles da água do Rio Atibaia (montante e jusante). Em novembro de 2001 o valor de OD do efluente foi aproximadamente zero, o que pode ter acarretado a inibição do processo de nitrificação, visto que este exige um consumo de aproximadamente 4,6 mg. $\mathrm{L}^{-1}$ de $\mathrm{O}_{2}$ para cada litro de nitrogênio amoniacal oxidado, Ferreira (2000). Esta diminuição dos valores de OD provavelmente induziu o aumento dos valores de $\mathrm{NH}_{3}$ neste mesmo período, chegando a $75 \mathrm{mg} . \mathrm{L}^{-1}$ (Figura 4).

No período de julho de 2002 a março de 2003, os valores de OD do efluente na saída da lagoa de estabilização foram acima ou iguais àqueles medidos na água do Rio Atibaia (montante e jusante), e superiores àqueles medidos no período de julho a dezembro de 2001, sugerindo uma recuperação, provavelmente ocorrida em função da implantação do novo sistema de tratamento de efluentes.

Comparando-se os dados de OD com a vazão média mensal do Rio Atibaia (Figura 6), não se observou influência direta da vazão sobre os valores de OD medidos à montante e à jusante da refinaria. Esses valores, em média sempre próximos de 7,0 mg. $\mathrm{L}^{-1}$, sugerem uma boa qualidade deste corpo hídrico - segundo este parâmetro - nestes pontos de análise. 


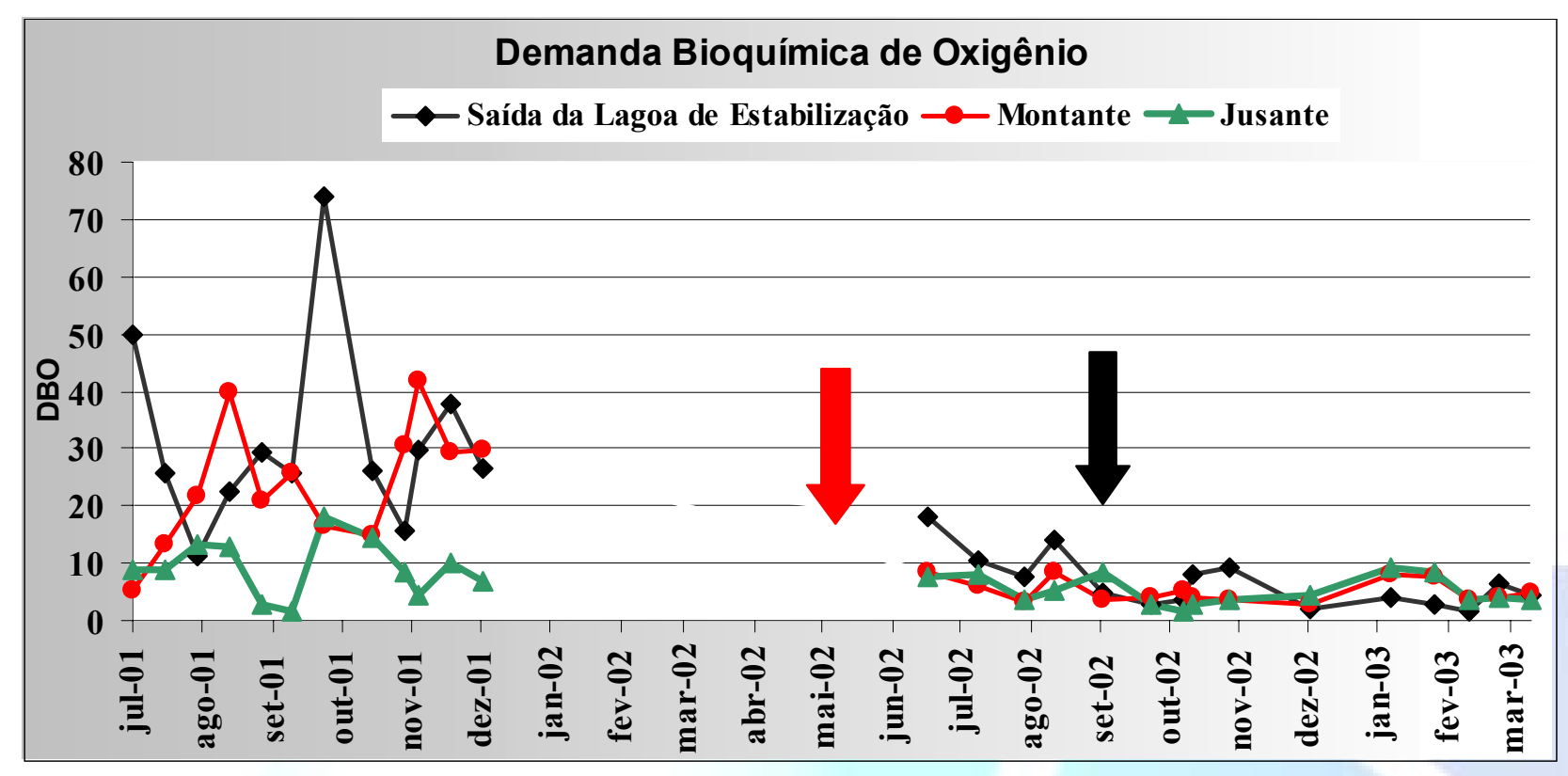

Figura 3 - Variação da demanda bioquímica de oxigênio expressa em mg.L. $\mathrm{L}^{-1}$ de $\mathrm{O}_{2}$ (5 dias) no período de julho de 2001 a março de 2003. A seta vermelha indica o início do novo sistema de tratamento e a seta preta indica o término da implantação do sistema de efluentes da indústria.

A DBO do efluente demonstrou valores mais altos no período pré-instalação do novo sistema de tratamento, comparativamente ao período pós-instalação. Este fato está associado à melhora do sistema de oxigenação do tratamento. Como a DBO expressa a quantidade de matéria orgânica biodegradável oxidativamente, sem oxigênio este processo não ocorre, (FELLENBERG, 1980).

O maior valor de DBO do efluente da refinaria observado no período foi em outubro de 2001, comparando-se o valor de OD do mesmo período (3,3 mg. $\left.\mathrm{L}^{-1}\right)$, contatou-se a diminuição da biodegradação da matéria orgânica do efluente em função da falta de OD. No entanto, o mesmo aumento da DBO não foi verificado em novembro de 2001, quando o valor de OD foi próximo de zero, pelo contrário, os valores de DBO diminuíram neste período. Este fato pode estar relacionado com a degradação anaeróbia da matéria orgânica, considerando-se que o OD no efluente era escasso. Como um dos produtos da degradação anaeróbia pode ser a $\mathrm{NH}_{3}$, este fato pode explicar a grande produção deste composto no mesmo período (Figura 4).

Verificou-se que os valores de DBO diminuíram na lagoa de estabilização, e também à montante e à jusante do Rio Atibaia, no período de junho de 2002 a março de 2003, comparativamente a 2001, demonstrando melhora deste parâmetro na água do rio. No entanto, este fato parece não estar associado à melhora nas condições do efluente, visto que os valores de $\mathrm{DBO}$ diminuíram também à montante e à jusante do descarte do efluente no rio. A melhora das condições do efluente na saída da lagoa de estabilização foi claramente observada após a implantação do novo sistema de tratamento. 


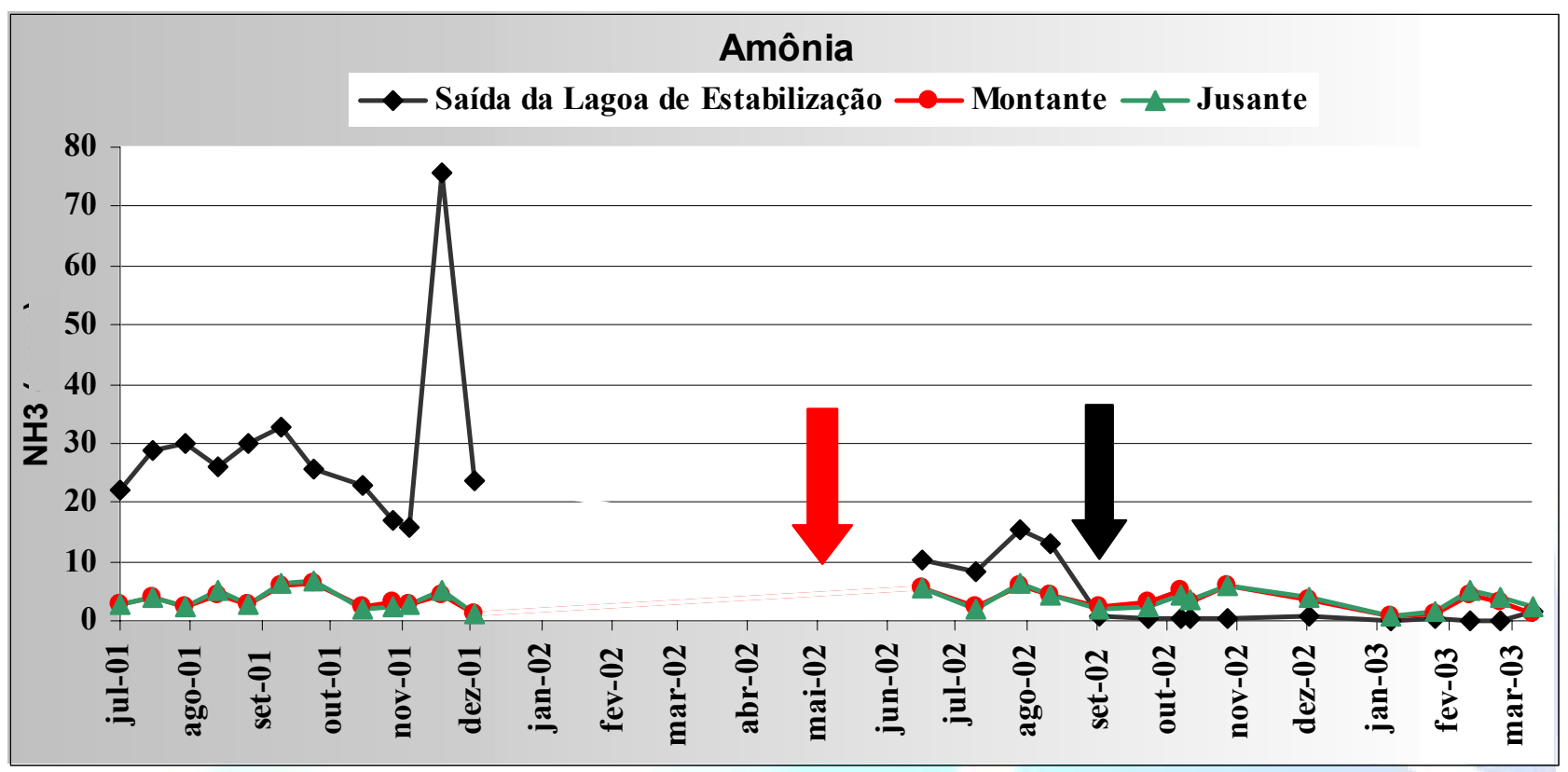

Figura 4 - Variação da amônia expressa em mg. $\mathrm{L}^{-1}$ de $\mathrm{NH}_{3}$, no período de julho de 2001 a março de 2003. A seta vermelha indica o início do novo sistema de tratamento e a seta preta indica o término da implantação do sistema de efluentes da indústria.

A amônia, substância tóxica para os organismos aquáticos (METTING, 1992), constituía um problema no processo de tratamento do efluente da Refinaria de Paulínia. No entanto, após a implantação do novo processo, e principalmente quando o mesmo foi encerrado, houve uma significativa diminuição nos valores deste parâmetro. As quantidades de $\mathrm{NH}_{3}$ ficaram próximas de zero, sendo menores que os valores encontrados no próprio Rio Atibaia. A semelhança do que foi verificado para a DBO, este fato é derivado da melhora do sistema de oxigenação do processo de tratamento, fato este que induz a nitrificação (FERREIRA, 2000).

Quanto aos pontos de coleta à montante e à jusante da refinaria não foram verificadas alterações no período, sendo que os valores apresentam-se abaixo de 5 mg. $\mathrm{L}^{-1}$ de $\mathrm{NH}_{3}$, sugerindo que, quanto a este parâmetro, a $\mathrm{NH}_{3}$ oriunda do efluente da refinaria não exercia influência na água do Rio Atibaia. Porém, a presença desta substância acima dos valores exigidos pela Legislação Brasileira (Resolução CONAMA 20/86), que é de $5 \mathrm{mg} . \mathrm{L}^{-1}$ é perigosa para a vida aquática. 


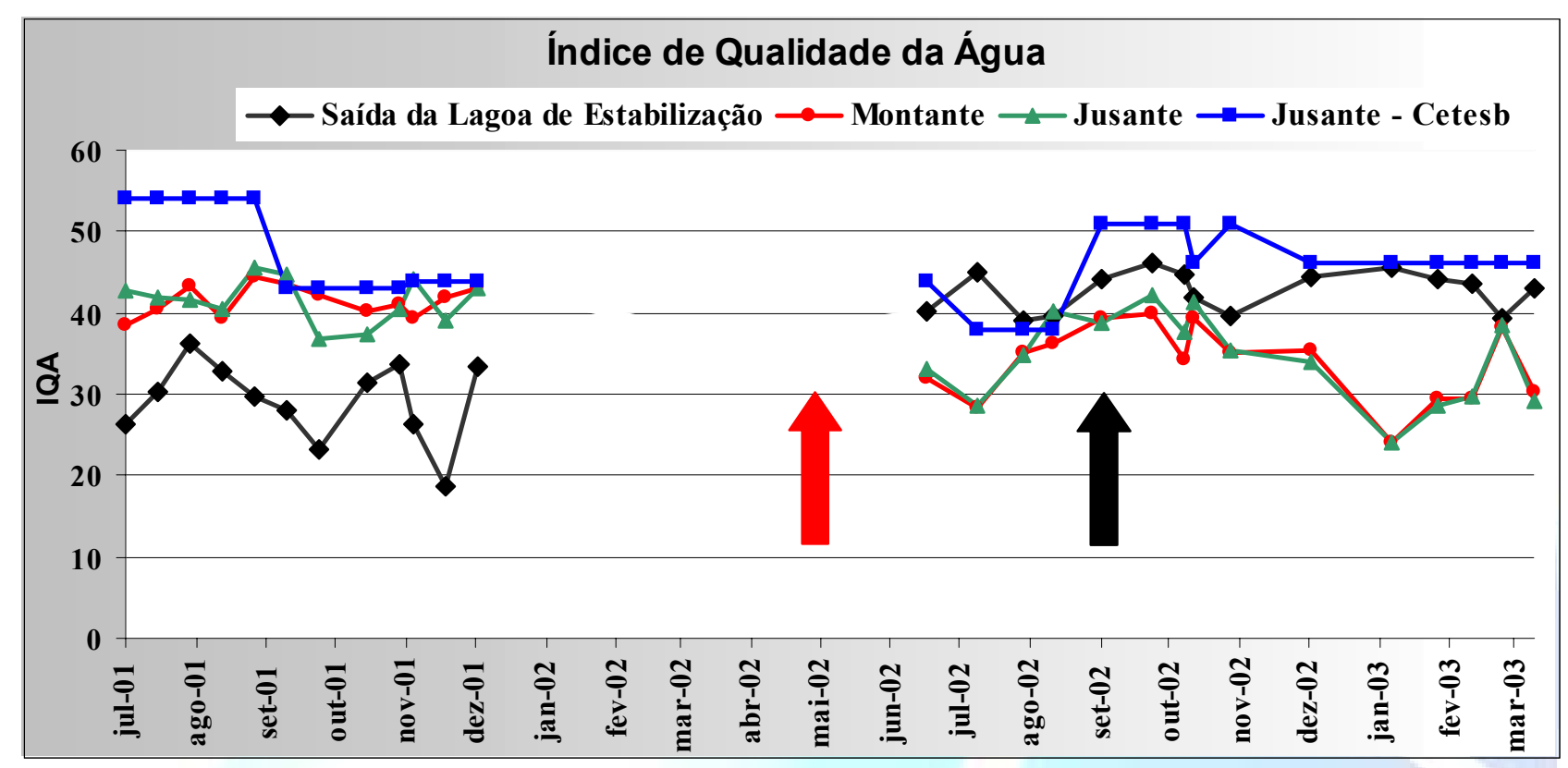

Figura 5 - Variação do índice de qualidade da água (IQA), no período de julho de 2001 a março de 2003. A seta vermelha indica o início do novo sistema de tratamento e a seta preta indica o término da implantação do sistema de efluentes da indústria.

A variação dos índices de qualidade da água (Figura 5), mostra que a água do Rio Atibaia nos dois pontos analisados recebeu classificação regular no período de julho a dezembro de 2001, assim como os valores indicados pela CETESB (2002). No período de junho de 2002 a março de 2003 o IQA apresentou uma ligeira queda, nos pontos à montante e à jusante da refinaria, recebendo classificação ruim para estes períodos. No ponto de coleta da CETESB (ponto 4, Figura 1), o IQA apresentou valores mais altos com relação aos pontos à montante e à jusante da refinaria (pontos 1 e 3), porém com a classificação - regular.

O IQA com classificação regular indica que o Rio Atibaia recebe aporte de poluentes neste trecho, e a classificação ruim indica que nestes períodos a qualidade da água do rio foi comprometida.

O IQA calculado para o efluente da refinaria obteve classificação ruim, no período de julho a dezembro de 2001, e regular de junho de 2002 a março de 2003, indicando a melhoria da qualidade do efluente neste período, resultado da melhoria no sistema de tratamento.

De maneira geral, o IQA apresentou valores semelhantes à jusante e à montante da refinaria, sugerindo que quanto a esse parâmetro não houve influência do descarte do efluente da refinaria sobre este parâmetro no Rio Atibaia.

Segundo CETESB (2002), o IQA apresenta algumas limitações, como a possibilidade de superestimar a qualidade da condição real do recurso hídrico (tendo em vista que contempla somente 9 parâmetros) e restringir-se a uma avaliação limitada somente utilizada para fins de abastecimento público. Não é possível 
estabelecer, por exemplo, indicação de qualidade ou toxicidade para a vida aquática utilizando este índice.

Os resultados demonstram que o sistema de tratamento implantado melhorou os parâmetros analisados. No entanto, isso não significa um tratamento ideal, que seria evidenciado, por exemplo, com índice de qualidade da água do efluente com classificação ótima.

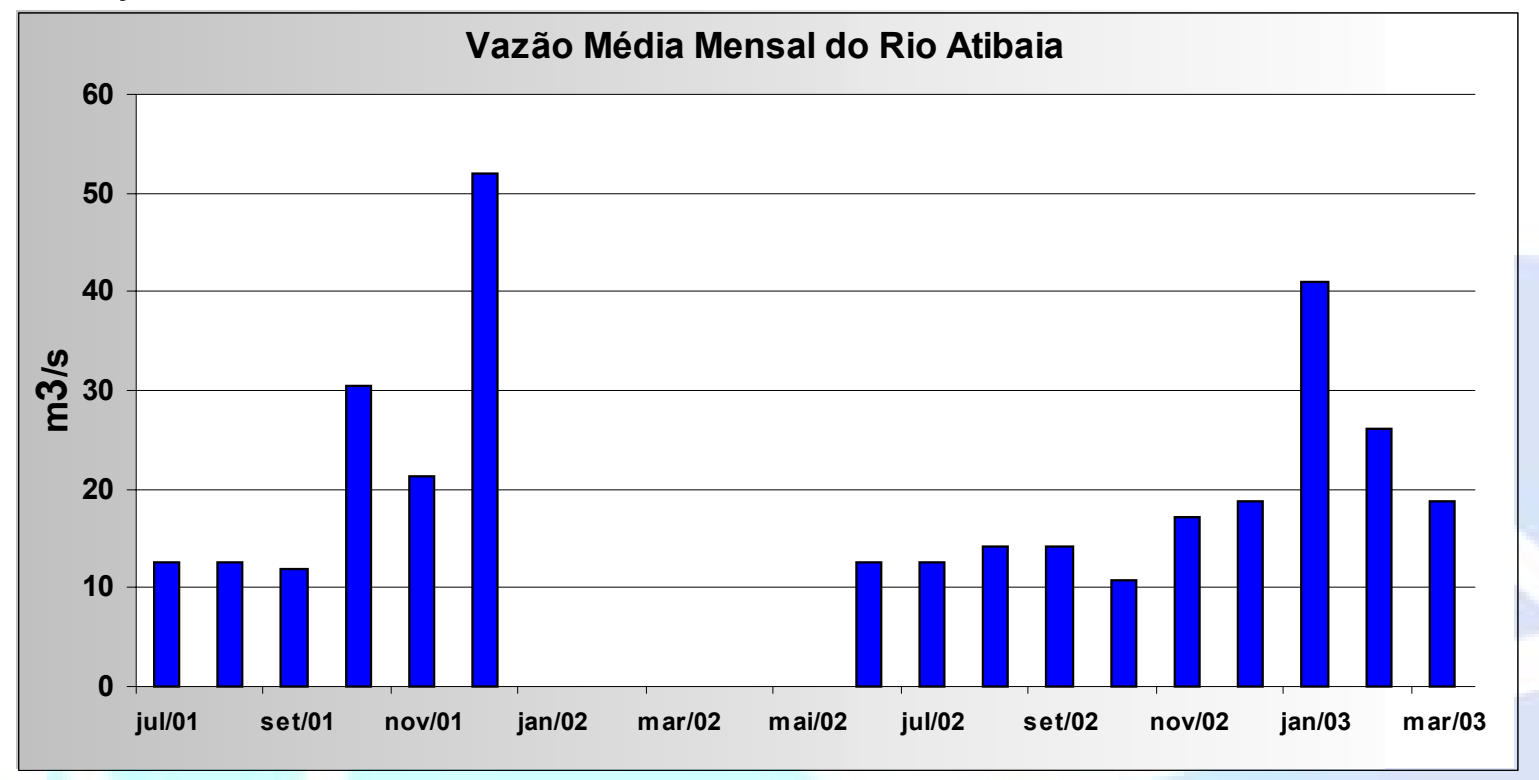

Figura 6 - Variação da vazão média mensal do rio Atibaia $\mathrm{m}^{3 / \mathrm{s}}$, no ponto 4 , no período de julho de 2001 a março de 2003.

\subsection{Análise Estatística}

A Figura 5 indica que, o IQA aumentou pós-instalação do novo processo no sistema de tratamento da refinaria, passando do valor médio de 29 para 44 . Ou seja, alterou sua classificação de ruim para regular. O teste t realizado para este parâmetro indicou aumento significativo no IQA, com valor de $(p<0,05)$. Isso demonstra que o sistema de tratamento apresentou melhora segundo este parâmetro.

$\mathrm{O}$ valor médio de OD apresentou aumento de 5 para $8 \mathrm{mg} \cdot \mathrm{L}^{-1}$ de $\mathrm{O}_{2}$ após a instalação do novo processo. O teste mostrou diferença significativa com $(\mathrm{p}<0,05)$. Quanto a DBO, houve diminuição dos valores médios de 30 para $5 \mathrm{mg} . \mathrm{L}^{-1}$ de $\mathrm{O}_{2} / \mathrm{L}$, com diferença significativa, sendo o valor de $(\mathrm{p}<0,05)$. O mesmo ocorreu para $\mathrm{NH}_{3}$, onde houve diminuição dos valores médios de 29,7 para $0,47 \mathrm{mg} . \mathrm{L}^{-1}$, após a implantação do novo sistema de tratamento. $\mathrm{O}$ teste mostrou diferença significativa nos valores de $\mathrm{NH}_{3}$, sendo $(\mathrm{p}<0,05)$. 


\begin{tabular}{|l|r|}
\hline Recebido em: $28 / 09 / 2004$ & HOLOS Environment, v.5 n.1, 2005 - P. 34 \\
\hline Liberado para Publicação em: $24 / 05 / 2005$ & ISSN: $1519-8634$ \\
\hline
\end{tabular}

IQ A

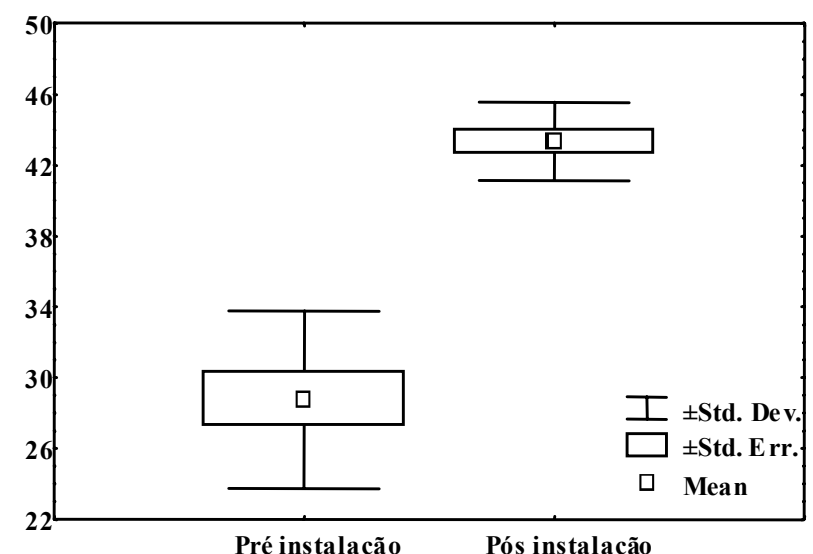

$\mathrm{DBO}(\mathrm{mgO2} / \mathrm{L}) 5$ dias

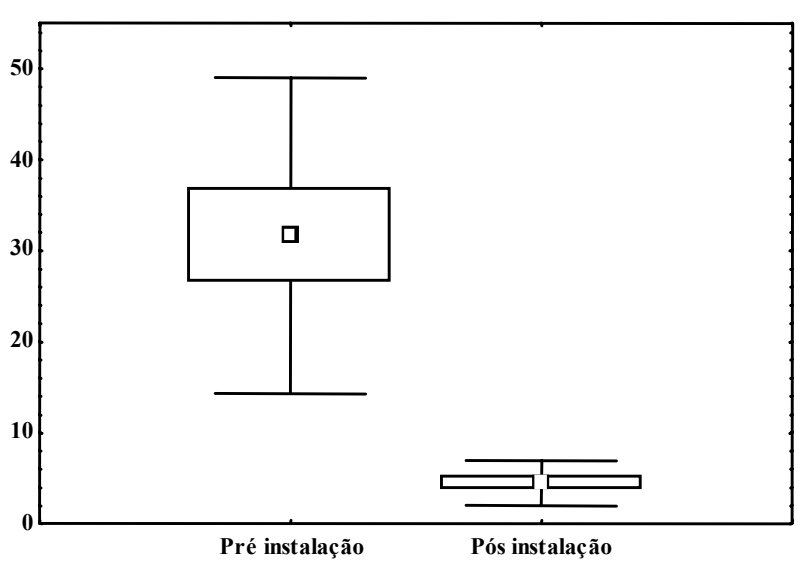

Oxigênio Dissolvido (ppm)
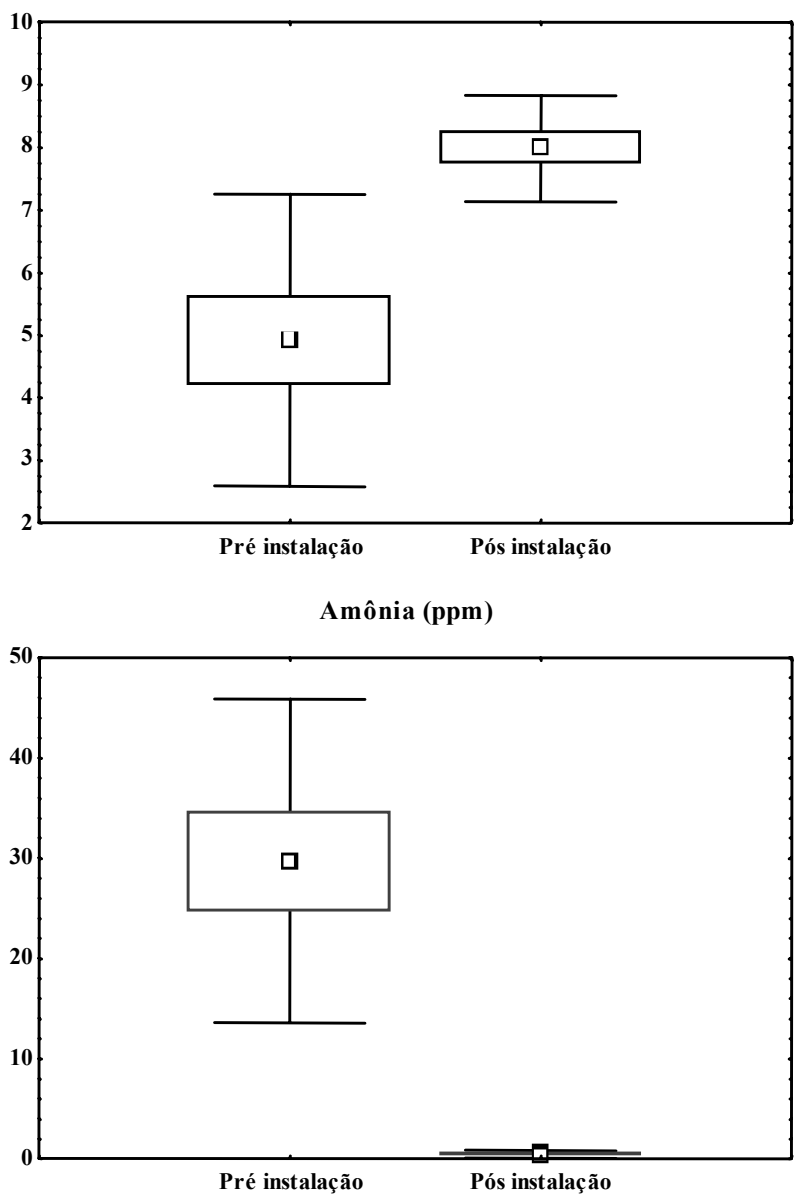

Figura 7 - Valores médios dos parâmetros do efluente da lagoa de estabilização calculados préinstalação e pós-instalação. As barras verticais indicam o desvio padrão e os retângulos indicam o erro padrão.

\section{CONCLUSÃO}

A análise das características químicas, físicas e do Índice de Qualidade da Água (IQA) do efluente da refinaria de petróleo REPLAN/PETROBRAS mostrou que o novo processo no sistema de tratamento da refinaria melhorou os parâmetros analisados. Os resultados mostraram que a melhoria da oxigenação do sistema contribuiu para a diminuição de $\mathrm{NH}_{3}$ para valores próximos de zero, além de minimizar os valores de DBO, conseqüentemente melhorando o Índice de Qualidade da Água do efluente.

O Sistema de Tratamento implementado pela REPLAN melhorou as condições de tratamento biológico do efluente. No entanto, isso não significa um sistema ideal, ou seja, a melhoria do sistema de tratamento deve, e está sendo efetuada no sentido de melhorar constantemente os parâmetros de qualidade da água. 


\section{AGRADECIMENTOS}

À refinaria de Paulínia REPLAN/PETROBRAS, que por meio dos projetos de pesquisa 270.2.061.01.8 e 270.4.097.03.0 colaborou com este estudo.

À equipe do Departamento de Bioquímica e Microbiologia da UNESP-Rio Claro que participou dos projetos de pesquisa.

Ao Programa de Formação de Recursos Humanos (PRH) da Agência Nacional do Petróleo (ANP), pelo auxílio concedido através do Programa de Formação de Recursos Humanos da UNESP-Campus de Rio Claro - PRH-05.

Aos revisores, pelas sugestões conferidas ao trabalho.

\section{REFERÊNCIAS}

BRITO, I. R. C. Efluentes de Refinaria de Petróleo: seleção de bactérias autóctones com potencial de biodegradação e redução de toxicidade aguda. 1996. 186f. Dissertação (Mestrado Microbiologia Aplicada) Instituto de Biociências, Universidade Estadual Paulista, Rio Claro.

COMPANHIA DE TECNOLOGIA E SANEAMENTO AMBIENTAL. Avaliação da toxicidade de despejos industriais na região da Grande São Paulo. São Paulo, 1987. 92p.

COMPANHIA DE TECNOLOGIA E SANEAMENTO AMBIENTAL. Relatório de qualidade das águas interiores do Estado de São Paulo de 2001. São Paulo. 2002. v.1,27p.

COMPANHIA DE TECNOLOGIA E SANEAMENTO AMBIENTAL. Relatório de qualidade das águas interiores do Estado de São Paulo de 2002. São Paulo. 2003. v.1, 156p.

COMPANHIA DE TECNOLOGIA E SANEAMENTO AMBIENTAL. Relatório de qualidade das águas interiores do Estado de São Paulo de 2003. São Paulo. 2004. v.1, 156p.

CONSELHO NACIONAL DO MEIO AMBIENTE. Resolução CONAMA 20. Brasília: SEMA. 1986. 98 p.

CONEGlian, C. M. R. Diminuição da Concentração de Amônia de Efluente Industrial PETROBRAS/REPLAN. 2001. 138f. Tese (Doutorado em Microbiologia Aplicada) Instituto de Biociências, Universidade Estadual Paulista, Rio Claro. 
CLESCERI, L. S.; GREENBERG, A. E.; TRUSSEL, R. R. Standard Methods for the Examination of Water and Wastewater. $20^{\text {th }}$.ed. Washington: American Public Health Association, 1998. 698p.

DUFFUS, J. H. Toxicologia ambiental. Barcelona. Omega, 1983. 173p.

EMPRESA BRASILEIRA DE PESQUISA AGROPECUÁRIA. Projeto Brasil Visto do Espaço. Imagens de Satélite LANDSAT 5 e 7. Cartas SF-23-Y-A-V-2-SO e SF23-Y-A-V-2-SE. Disponível em <www.dcbrasil.cnpm.embrapa.br $>$. Acesso em 15 jan. 2004.

FELLENBERG, G. Introdução aos problemas da poluição ambiental. São Paulo: EDUSP, 1980. 196p.

FERREIRA, E. S. Cinética química e fundamentos dos processos de nitrificação e denitrificação biológica. Rio de Janeiro. Associação Brasileira de Engenharia Sanitária e Ambiental, 2000. 48p.

GOLDSTEIN, G. E. Testes de toxicidade de efluentes industriais. AMBIENTE, São Paulo, v.2, n.1, 33-38p, 1998.

LANDIS, W. G.; YU, M.H. Introduction to Environmental toxicology: Impacts of Chemicals Upon Ecological Systems. Boca Raton: Lewis, 1985. 328p.

METTING, F. B. Soil microbial ecology: applications in agricultural and environmental management. New York: Marcel Dekker, 1992. 527p.

WIECZOREK, A; ANGELIS, D. F.; KATAOKA, A. P. A. G.; CONEGLIAN, C. M. R.; OLIVEIRA, V. J. A. Análise de Parâmetros Físicos, Químicos e Toxicológicos da Água do Rio Atibaia à Jusante e à Montante da Refinaria Replan/Petrobras. In: CONGRESSO BRASILEIRO DE PESQUISA E DESENVOLVIMENTO EM PETRÓLEO E GÁS, 2: 2003, Rio de Janeiro. Anais...Rio de Janeiro, 2003.

VON SPERLING, M. V. Princípios do tratamento biológico de águas residuárias - Lodos Ativados. Minas Gerais: Departamento de Engenharia Sanitária e Ambiental; Universidade Federal de Minas Gerais, 1997. v.4, 416p. ]

ZAR, J. H. Biostatiscal Analysis. ${ }^{\text {rd }}$ ed. New Jersey: Prentice Hall. 1996. 622p. 